\title{
Bois-bumbás de Parintins: síntese metafórica da realidade?*
}

\author{
Lydia Maria Pinto Brito** \\ Edinelza Macedo Ribeiro*** \\ Tereza de Souza****
}

SumÁrio: 1. Introdução; 2. Desenvolvimento local sustentável; 3. Dimensão sistêmica; 4. Dimensão cultural; 5. Metodologia; 6. Resultados obtidos; 7. Conclusões.

Summary: 1 . Introduction; 2 . Sustainable local development; 3. Systemic dimension; 4. Cultural dimension; 5. Methodology; 6. Results; 7. Conclusions.

Palavras-chave: desenvolvimento local integrado; cultura; boi-bumbá.

KEY WORDs: sustainable local development; culture; boi-bumbá.

Este artigo analisa como os atores sociais internos percebem o evento dos bois-bumbás da cidade de Parintins, tendo em vista o valor que tal fenômeno representa para a comunidade local nos aspectos culturais, econômicos e sociais, e por criar um espaço onde os seus integrantes possam refletir, falar e produzir conhecimento sobre sua realidade. Procurou-se identificar a percepção dos atores sociais internos sobre a influência desse fenômeno cultural nas dimensões sistêmica e cultural do desenvolvimento local sustentável (DLS) da cidade de Parintins. Os pressupostos que orientaram o estudo foram: elementos da cultura brasileira estão presentes na cultura local representada pelo contexto dos bois-bumbás; a cultura indígena amazônica dá significado aos

\footnotetext{
* Artigo recebido em mar. 2008 e aceito em maio 2009.

** Doutora em educação e mestra em sociologia pela Universidade Federal do Ceará (UFC). Professora do mestrado profissional de administração da Universidade Potiguar (UNP). Endereço: Rua Pereira Valente, 720, ap. 1000 - Meireles - CEP 60160-250, Fortaleza, CE, Brasil. E-mail: lydiampbrito@yahoo.com.br.

**** Aluna do mestrado profissional de administração da UNP. Professora do Centro de Estudos Superiores de Parintins da Universidade do Estado do Amazonas. Endereço: Av. Amazonas, 2642 — Centro - CEP 69151-000, Parintins, AM, Brasil. E-mail: ediribeiro27@hotmail.com.

**** Doutora em administração de empresas pela Escola de Administração de Empresas de São Paulo da FGV. Mestra em administração pela Universidade Federal de Minas Gerais (UFMG). Coordenadora e professora do mestrado profissional de administração da UNP. Endereço: Av. Floriano Peixoto, 295 — Petrópolis — CEP 59012-500, Natal, RN, Brasil. E-mail: terezasouza@unp.br.
} 
elementos que possibilitam a construção dos bois-bumbás; e o boi-bumbá está se transformando em mercadoria subsumida às necessidades do capital. O referencial de análise baseou-se principalmente nos conceitos de DLS, modo de produção capitalista e cultura. A metodologia utilizada foi de natureza qualitativa. As conclusões sinalizam para a confirmação dos pressupostos.

Bois-Bumbás of Parintins: metaphoric synthesis of reality?

This article investigates on how the inside social actors perceive the boi-bumbá celebrations in the town of Parintins, Brazil, considering the value that such phenomenon represents to the local community in its cultural, economic and social aspects, as well as the opportunity for the participants to reflect on, speak about and produce knowledge on their own reality. The investigation identified how such actors perceive the influence of this social phenomenon in the systemic and cultural dimensions of the town's sustainable local development (SLD). The hypotheses that guided the study were: elements of the Brazilian culture are present in the local culture represented by the boi-bumbá context; the native Amazonian culture gives signification to the elements that allow the construction of the bois-bumbás; the boi-bumbá is becoming a merchandise submitted to the capital's demands. The analytical framework was based mostly in the concepts of SLD, capitalist production system and culture. The investigation adopted a quantitative method. The conclusions confirm the hypotheses.

\section{Introdução}

No Brasil, o projeto de desenvolvimento surgiu nos anos 1950, com foco na dimensão econômica e como produto de posicionamentos impulsionados a partir dos governos centrais, e não como consequência de iniciativas territoriais geradas da base. As discussões em torno dessa temática travavam-se "entre uma corrente que defendia o liberalismo econômico, preocupada em garantir a 'vocação agrária' do Brasil, e uma corrente desenvolvimentista, que pregava a intervenção do Estado na economia para implementar a industrialização no país" (Mantega, 1987:12). Dos anos 1970-80 em diante, a crise do modelo de desenvolvimento capitalista focado no econômico, que se mostrou concentrador e baseado na grande indústria e nos grandes núcleos urbanos, estimulou maior interesse na reflexão sobre as iniciativas de desenvolvimento local. Foram constatadas igualmente as limitações das políticas macroeconômicas formuladas desde as instâncias centrais, quando se trata de conseguir um crescimento mais equilibrado territorialmente, mais equitativo do ponto de vista da distribuição da renda e mais ambientalmente sustentável; em suma, com capacidade para impulsionar o desenvolvimento humano e elevar a qualidade de vida da população de regiões mais pobres. Nas últimas duas décadas, os 
estudos de caso mostram o surgimento de experiências com nova alternativa de desenvolvimento, surgida de forma espontânea e dispersa, denominada desenvolvimento local sustentável (DLS) e que supõe a emergência de atores sociais, formação de redes de cooperação, elaboração de projetos coletivos e institucionalização. O município de Parintins, no Amazonas, parece sinalizar para esse tipo de alternativa de desenvolvimento.

A questão fundamental de pesquisa deste artigo é: como os atores sociais percebem o fenômeno dos bois-bumbás de Parintins? Dessa forma, as questões complementares são: o fenômeno cultural dos bois-bumbás mobiliza e contribui na formação de atores sociais em Parintins? Existe no contexto do evento a formação de redes de atores sociais e parcerias entre a sociedade civil, poder público e patrocinadores? Há um projeto coletivo no contexto das organizações que realizam o evento cultural em estudo? Que modelo de sistema institucional é utilizado na promoção do evento? A pesquisa se justifica pelo valor que esse fenômeno representa para a comunidade local, nos aspectos culturais, econômicos e sociais, e por criar um espaço onde os integrantes do contexto local possam refletir, falar e originar conhecimento sobre sua realidade. O objetivo geral do artigo foi identificar a percepção dos atores sociais internos sobre a influência do fenômeno cultural dos bois-bumbás para o DLS da cidade de Parintins, nas dimensões sistêmicas e culturais. Os objetivos específicos foram: investigar se o fenômeno cultural dos bois-bumbás possibilita a emergência de atores sociais; verificar a existência de formação de redes de cooperação; identificar a existência de projetos coletivos; e identificar o modelo do sistema institucional utilizado na promoção do evento. Os pressupostos que orientaram o estudo foram: existem elementos da cultura brasileira presentes na cultura local, representada pelo evento dos bois-bumbás; a cultura indígena amazônica dá significado aos elementos que possibilitam a construção dos bois-bumbás; e o boi-bumbá está se transformando em mercadoria subsumida às necessidades do capital. O referencial de análise baseouse, entre outros, principalmente em autores e documentos institucionais que focalizam desenvolvimento local sustentável (Albuquerque, 1998; Cepal, 1990; Agenda 21, 1992; Buarque, 1998; Mantega, 1987; Brito, 2006; Teisserenc, 1994); modo de produção capitalista (Marx, 1985); e cultura (Schein, 1986; Motta e Miguel, 1997). A metodologia utilizada foi de natureza qualitativa.

\section{Desenvolvimento local sustentável}

Buarque (1998) caracteriza o DLS como um processo endógeno registrado em pequenas unidades territoriais e agrupamentos humanos, capaz de pro- 
mover o dinamismo econômico e a melhoria da qualidade de vida da população. A proximidade dos problemas, necessidades, recursos e atores sociais locais permitem formular políticas mais realistas e, sobretudo, baseadas no consenso com tais atores, capazes de "introduzir modalidades de ação nas quais os atores tenham maiores margens de autonomia nas decisões" (Cepal, 1990:917). Igualmente, se abre a possibilidade de promover a criação negociada de instituições de fomento produtivo empresarial no contexto local, de produzir um clima de confiança e cooperação entre entidades públicas e setor privado empresarial, e de estimular, assim, uma cultura local de desenvolvimento sustentável. Desse modo, a identidade cultural de cada território se converte em sustentação de seu desenvolvimento social e econômico. Para tanto, o desenvolvimento resulta do compromisso de uma parte significativa da sociedade local e de mudanças básicas em suas atitudes e comportamentos, o que permite substituir a concepção tradicional de "espaço" (como simples espaço físico) pela de um contexto social de cooperação ativa (um "território"). Assim, o desenvolvimento local sustentável pode ser entendido como aquele processo reativador da economia e dinamizador da sociedade local que, mediante o aproveitamento eficiente dos recursos internos disponíveis em uma zona determinada, é capaz de estimular seu crescimento econômico, criar emprego e melhorar a qualidade de vida da comunidade local. É esse potencial interno, quando realizado, que define o desenvolvimento local. Um projeto desse tipo deve ser assegurado mediante a mobilização da população local e seu concurso na formulação, implementação e monitoramento das iniciativas de desenvolvimento. Assim, entende-se que a globalização e o desenvolvimento local são dois polos de um mesmo processo complexo e contraditório, exercendo forças de integração e de segregação, dentro do intenso jogo competitivo mundial. Ao mesmo tempo em que ocorre a mundialização do capital, surgem crescentes iniciativas no nível local, com ou sem integração na dinâmica internacional, o que aponta para a possibilidade de processos diferenciados de desenvolvimento dentro do capitalismo (Cepal, 1990).

Enfim, a globalização tem um efeito dialético sobre a organização do espaço social. De um lado, demanda e provoca um movimento de uniformização e padronização dos mercados e produtos como forma de integrar os mercados; por outro, também provoca a diversificação e a flexibilização das economias e dos mercados locais, cria e produz diversidades, integrando os valores globais com os padrões locais e articulando o local ao global.

Para Milani (2003), o DLS envolve fatores sociais, culturais e políticos que não se regulam exclusivamente pelo sistema de mercado. $\mathrm{O}$ crescimento econômico é uma variável essencial, porém não suficiente para ensejar o de- 
senvolvimento local. Considerado como projeto para Perroux (apud Milani, 2003), caminho histórico para Sachs (apud Milani, 2003), e ação pluridimensional para Bártoli (apud Milani, 2003), o desenvolvimento local é marcado pela cultura do contexto onde está situado. Nesse sentido, pode ser considerado como um conjunto de atividades culturais, econômicas, políticas e sociais - vista sob a óptica intersetorial e transescalar — que participam de um projeto de transformação consciente da realidade local. Nesse desafio, há significativo grau de interdependência dos diversos segmentos que compõem a sociedade (âmbito cultural, político, legal, educacional, econômico, ambiental e tecnológico) e os agentes presentes em diferentes escalas econômicas e políticas - do local ao global (Milani, 2003).

Para este artigo, foram considerados como indicadores de sucesso da constituição do desenvolvimento local sustentável alguns fatores que funcionam como mecanismos de sustentação do processo:

v emergência de atores sociais - consiste na existência de uma situação favorável ao surgimento de sujeitos (lideranças comunitárias; diretores de serviços ou de agências de desenvolvimento; representantes institucionais; encarregados de funções; gerentes de projetos; empresários; operadores e representantes eleitos que sejam incentivadores ou não das políticas de desenvolvimento) cujo perfil de competência, em termos de conhecimentos, habilidades e atitudes, os predestinam a representar um papel particular na realização das políticas de desenvolvimento;

- formação de redes de cooperação - significa a capacidade dos atores sociais de desenvolvimento do sentimento de pertença ao grupo e da consciência de responsabilidade social, para promover uma articulação eficaz em redes de cooperação mútua dentro e fora da comunidade, estabelecendo comunicação, negociação e superação dos conflitos;

- desenvolvimento de projetos coletivos - representa a capacidade de formulação de referências conceituais formais e informais, que possam orientar e inspirar o alcance dos objetivos em função de acordos previamente estabelecidos e selecionados, concedendo significados pessoais e coletivos aos processos de mudança, impondo sentido à imaginação, à vontade, aos valores e à identidade cultural local (Brito, 2005, apud Teisserenc, 1994);

- criação de sistema institucional - que consiste no compromisso de criar estruturas empenhadas em promover as políticas de desenvolvimento local, como sistema social aberto para promover mudanças duráveis, integrar os atores e viabilizar os projetos coletivos, as agências de desenvolvimento, os 
serviços de economia de uma coletividade e as estruturas intermunicipais. Promove, também, a transformação dos serviços: serviços técnicos das coletividades, serviço do Estado e estruturas municipais e outros organismos de caráter privado ou não governamental.

O entendimento do DLS implica a articulação das duas dimensões fundamentais da realidade: a dimensão sistêmica - referente às conexões que fazem parte de uma realidade social mais ampla e complexa, surgida na modernidade com o capitalismo, e que se constitui um modelo de sistema autorregulado, principalmente pelo mercado e o Estado - mecanismos fora do sujeito; e a dimensão cultural — referente às interações intersubjetivas de cunho social, histórico e cultural entre os indivíduos. Este artigo apenas expressará algumas sinalizações das duas dimensões.

\section{Dimensão sistêmica}

O entendimento da realidade na perspectiva da dimensão sistêmica passa pela compreensão das categorias marxistas de análise (Marx, 1985). Elas são: totalidade (tudo está interconectado e em interação); materialismo (referente às condições materiais de existência da realidade concreta do cotidiano dos indivíduos); reprodução (o processo de acumulação do capital se reproduz desde o nível pessoa a pessoa - patrão e empregado, até a mundialização - país rico e país pobre); e alienação (o trabalhador não possui o resultado de seu trabalho).

Compreender as relações intersubjetivas no sistema capitalista é perceber as contradições de um modo de produção baseado no mercado e na sociedade de classes: o estrato capitalista, que detém o capital, a propriedade, os objetos de trabalho e os meios de produção e que explora o trabalho para obter mais-valia; e a camada trabalhadora, que vende sua força de trabalho. A força de trabalho é, assim, como tudo no capitalismo, transformada também em "mercadoria que tem o dom de criar valor maior do que nela está contido" (Teixeira, 1995:132).

Para Marx (1985:154), os fenômenos peculiares ao processo de trabalho capitalista são:

o trabalhador trabalha sob o controle do capitalista a quem pertence seu trabalho. O capitalista cuida de que o trabalho se realize em ordem e os meios de 
produção sejam empregados conforme seus fins, portanto, que não seja desperdiçada matéria-prima e que o instrumento de trabalho seja preservado.

E o produto do trabalho "é propriedade do capitalista, e não do produtor direto" (Marx, 1985:149), ou seja, não pertence ao indivíduo que realiza o trabalho.

Essa forma da divisão do trabalho fornece a lógica do modelo que se organiza para acumular capital nas mãos da classe burguesa e alienar o trabalhador, já que "o capitalista, mediante a compra da força de trabalho, incorporou o próprio trabalho, como fermento vivo, aos elementos mortos constitutivos do produto, que lhe pertencem igualmente" (Marx, 1985:154). Assim, "o produto - a propriedade do capitalista - é um valor de uso" (Marx, 1985:155), portador de um valor de troca, ou seja, "um artigo destinado à venda, uma mercadoria" (Marx, 1985:155); uma mercadoria cujo valor no mercado seja mais alto do que a soma dos valores das mercadorias exigidas para produzi-la, os meios de produção e o pagamento da força de trabalho (Marx, 1985:155). Finalmente, na lógica do capital, o capitalista, ao explorar o trabalho, quer produzir mercadoria, valor de uso, valor, e mais-valia (lucro). Lógica reproduzida mediante a ideologia burguesa para o conjunto da sociedade.

Neste artigo, serão considerados para exprimir a realidade sistêmica apenas alguns dados do índice de desenvolvimento humano (IDH). A elaboração do IDH tem como objetivo oferecer contraposição a outro indicador, o produto interno bruto (PIB), e parte do pressuposto de que, para dimensionar o avanço, não se deve considerar apenas a dimensão econômica, mas também outras características sociais, culturais e políticas que influenciam a qualidade da vida humana. No IDH estão equacionados três subíndices direcionados às análises: educacionais, de renda e de longevidade de uma população. O resultado das análises educacionais é medido por uma combinação da taxa de alfabetização de adultos e a taxa combinada nos três níveis de ensino (fundamental, médio e superior). Já o resultado do subíndice renda é medido pelo poder de compra da população, baseado pelo PIB per capita ajustado ao custo de vida local para torná-lo comparável entre países e regiões, por meio da metodologia conhecida como paridade do poder de compra (PPC). E, por último, o subíndice longevidade tenta refletir as contribuições da saúde da população medida pela esperança de vida ao nascer. A metodologia de cálculo do IDH envolve a transformação dessas três dimensões em índices de longevidade, educação e renda, que variam entre 0 (pior) e 1 (melhor), e a combinação desses índices em um indicador síntese. Quanto mais próximo de 1 o valor 
desse indicador, maior será o nível de desenvolvimento humano do país ou região (Pnud, 2000).

\section{Dimensão cultural}

Para Mota e Miguel (1997:34),

a cultura fornece aos grupos e às nações um referencial que permite aos homens atribuir um sentido ao mundo no qual vivem e às suas próprias ações. A cultura designa, classifica, corrige, liga e coloca em ordem. (...) A cultura é um sistema de símbolos e significados compartilhados, que serve como mecanismo de controle. A ação simbólica necessita ser interpretada, lida ou decifrada para que seja entendida (...) Toda cultura é caracterizada por algum nível de continuidade.

Schein (apud Freitas, 1991) vislumbra a cultura como um aprendizado coletivo ou compartilhado, que uma unidade social ou qualquer grupo desenvolve como sua capacidade para fazer face ao ambiente externo e lidar com suas questões internas. Dessa forma, para Schein (apud Fleury, 1996:24),

a cultura é formada pelo o conjunto de pressupostos básicos que um grupo inventou, descobriu ou desenvolveu, ao aprender a lidar com os problemas de adaptação externa e integração interna e que funcionaram bem o suficiente para serem considerados válidos e ensinados a novos membros como a forma correta de perceber, pensar e sentir com relação a esses problemas.

Numa perspectiva antropológico-cultural constatam-se, em Sathe (apud Freitas, 1991) duas correntes principais: a adaptacionista, que defende a cultura como algo diretamente observável nos membros de uma comunidade, isto é, seus padrões de comportamento, discurso e uso de objetos materiais; e a dos defensores da escola ideacional, os quais definem a cultura como algo compartilhado na mente dos membros da comunidade, como crenças, valores e ideias que as pessoas sustentam em comum. Freitas (1991) sistematiza os diversos conceitos em diferentes abordagens: a antropologia cognitivista, dirigida aos conhecimentos compartilhados; a antropologia simbólica, dirigida aos significados compartilhados; e a antropologia estrutural, focada nos processos psicológicos inconscientes. Este artigo mostra que a cultura é um conjunto complexo e dinâmico de elementos materiais e simbólicos compartilhados, do 
ponto de vista intelectual e psicológico, e que orientam a ação humana num contexto histórico e geográfico.

No Brasil, vários estudos clássicos (Cunha, 1995; Freire, 1995; Holanda, 1994; Faoro, 1989; Fernandes, 1987; Prado Jr., 1987) foram elaborados no sentido de mapear sinalizações dos traços da cultura brasileira.

Quadro 1

\section{Sinalizações de traços da cultura brasileira}

\begin{tabular}{|c|c|}
\hline Traço & Características-chave \\
\hline Hierarquia & $\begin{array}{l}\text { Autoritarismo. Tendência à centralização do poder dentro dos grupos sociais. } \\
\text { Distanciamento nas relações entre diferentes grupos sociais (Faoro, 1989). }\end{array}$ \\
\hline Personalismo & $\begin{array}{l}\text { Sociedade baseada em relações afetivas. Paternalismo: domínio moral e econômico. } \\
\text { Mistura do público com o privado (Holanda, 1994). }\end{array}$ \\
\hline Malandragem & $\begin{array}{l}\text { Flexibilidade e adaptabilidade como meio de navegação social. "Jeitinho" (Holanda, } \\
\text { 1994). }\end{array}$ \\
\hline Sensualismo & Gosto pelo exótico e sensual nas relações (Freire, 1995). \\
\hline Conservador & $\begin{array}{l}\text { Elite burguesa promove mudança para não mudar a situação e o consequente processo } \\
\text { de acumulação (Fernandes, 1987; Prado Jr., 1987). }\end{array}$ \\
\hline Religiosidade & $\begin{array}{l}\text { Indivíduo busca solução para o problema amparado por uma entidade metafísica e } \\
\text { religiosa. Sincretismo religioso. Mistura entre o profano e o sagrado (Cunha, 1995). }\end{array}$ \\
\hline
\end{tabular}

Fonte: Adaptado de Freitas, apud Motta e Miguel (1997:44).

Na realidade, esse conjunto de fatores ilustra um dos fascinantes lugares de tensa e intensa troca cultural, tão característicos da cultura brasileira. Eles seriam fruto da constituição histórica do país e poderiam ou não emergir nas diversas especificidades locais. Hofstede (apud Motta e Miguel, 1997), com relação aos valores culturais relacionados ao trabalho, entende que no Brasil existe grande distância entre os trabalhadores e a elite que se encontra no poder, traço relacionado à hierarquização social. As origens patriarcais brasileiras geraram o hábito da obediência irrestrita a uma minoria social e a aceitação da estratificação por cor, dinheiro ou nome de família. Concentração e estratificação têm, certamente, implicações na forma de relacionamento comunitário e organizacional que deixa de ser de sujeito para sujeito iguais para ser de superior e subordinado. Nesse contexto, as relações afetivas surgem como alternativa de navegação social, a sensualidade como estratégia de sedução e manipulação e a religiosidade como uma possibilidade de saída da materialidade do cotidiano. É importante também registrar que no século XX a cultura deixa de ser uma área de desenvolvimento espontâneo de enrique- 
cimento do espírito, para se tornar mais um setor que tem que "se sustentar", como "negócios privados" apoiado por verbas governamentais (Wu, 2006).

\section{Metodologia}

Esta pesquisa, de natureza qualitativa (Dezin e Lincoln, 2003; Flick, 2004) privilegiou a percepção dos sujeitos que atuam diretamente na organização do evento dos bois-bumbás da cidade de Parintins. Com relação aos objetivos, é uma pesquisa descritiva. Quanto aos métodos de procedimento, foi feito um estudo de caso (Yin, 2005).

Das duas organizações - Associação Folclórica Bois-bumbás Caprichoso (AFBBC) e Associação Folclórica Bois-bumbás Garantido (AFBBG) — foram entrevistados os sujeitos que trabalham diretamente no projeto dos bumbás e que atuam na parte técnico-administrativa. São 10 sujeitos que exercem papéis importantes no contexto das organizações, em razão de competências e representatividades diante da função que a comunidade lhes confia. Entre eles encontram-se: dois presidentes das associações folclóricas, dois diretores de teatro (Boi de Arena), dois apresentadores/animadores, dois responsáveis pela batucada e dois levantadores de toadas. Como técnica de investigação, foi adotada a entrevista semiestruturada, com cerca de 40 perguntas. As falas dos sujeitos foram registradas e a análise foi feita por meio de ideias sínteses e a comparação das falas obtidas. As variáveis analíticas que, articuladas, permitiram a realização do estudo, foram: desenvolvimento local sustentável - emergência de atores sociais, formação de redes, elaboração de projetos coletivos e instituições; modo de produção capitalista; e cultura/cultura brasileira. Diante da riqueza dos dados obtidos e o pequeno espaço disponível neste artigo, somente algumas falas emblemáticas foram relatadas.

\section{Resultados obtidos}

\section{Os bois-bumbás de Parintins}

Dimensão sistêmica da realidade. Parintins, município do estado do Amazonas, está situado na ilha Tupinambarana, à margem direita do rio Amazonas, divisa com o Pará. O município encontra-se a $420 \mathrm{~km}$ a leste de Manaus por via fluvial e $325 \mathrm{~km}$ em linha reta, com área de $7 \mathrm{mil} \mathrm{km} \mathrm{km}^{2}$. De acordo com o censo de 2007, tem uma população com aproximadamente 101.908 habitan- 
tes, sendo que 66.481 vivem na área urbana e 35.427 vivem na área rural. A população economicamente ativa do local sobrevive do extrativismo, pesca e pecuária. Esta última atividade, inclusive, preocupa os ambientalistas em virtude da grande derrubada e da queimada de florestas nativas que a cada ano sofrem com o processo devastador de transformação de campos para criação de gado de corte pelos grandes proprietários. Outro fator preocupante na região diz respeito à escassa produção agrícola, com respeito a produtos de subsistência para a população local. Esse fato contribui com a baixa qualidade da alimentação do povo da região. A maioria da produção agrícola consumida vem de outras regiões. Isso reflete no custo elevado dos preços da alimentação básica e, consequentemente, a dificuldade de acesso desses alimentos às populações mais necessitadas, que se alimentam basicamente de peixe e farinha.

O IDH do município de Parintins segundo o Pnud (2000), é de 0,696 numa escala de 0 a 1 , o que indica uma situação de médio desenvolvimento humano.

\section{Tabela 1}

Indicadores gerais de IDH de Parintins

\begin{tabular}{|lccc|}
\hline Indicadores & 1991 & $\mathbf{2 0 0 0}$ & Diferença (\%) \\
\hline IDH & 0,658 & 0,696 & 5,78 \\
Educação & 0,791 & 0,855 & 56,1 \\
Longevidade & 0,636 & 0,705 & 60,7 \\
Renda & 0,546 & 0,527 & $-16,7$ \\
\hline
\end{tabular}

Fonte: Pnud, 2000.

Focando, porém, os subíndices-chave da análise - educação, renda e longevidade da população - , temos, de acordo com a tabela 1, que, embora a educação e a longevidade tenham melhorado no período de 1991-2000, a renda caiu em $16,7 \%$.

Tabela 2

Indicadores de origem da renda de Parintins

\begin{tabular}{|lrr|}
\hline Indicadores & 1991 & 2000 \\
\hline Renda proveniente de transferências governamentais (\%) & 8,61 & 16,04 \\
Renda proveniente de rendimentos do trabalho (\%) & 82,35 & 65,33 \\
Pessoas com mais de 50\% da renda provenientes de transferências governamentais (\%) & 6,05 & 14,56 \\
\hline
\end{tabular}

Fonte: Pnud, 2000.

RAP - RIO DE JANEIRO 44(1):7-30, JAN./FEV. 2010 
Verifica-se que, num período de 10 anos, a renda proveniente de rendimento com o trabalho diminuiu e que houve aumento de rendas provenientes de transferências governamentais. A renda per capita média, considerando R\$ 2 mil, caiu de $102,7 \%$ para $91,7 \%$, o que pode significar o empobrecimento da população.

A pacata cidade transfigura-se anualmente, quando recebe cerca de 50 mil visitantes, para abrigar uma festa espetacular: o Festival dos Bois-Bumbás. O festival acontece nas três últimas noites do mês de junho e organiza-se em torno da competição entre dois grupos folclóricos, assim representados: Boi Garantido, considerado o boi do "povão", cujas colorações emblemáticas são o vermelho e o branco; e Boi Caprichoso, percebido pelas pessoas como o boi da elite, simbolizado nos tons preto e azul. O espetáculo acontece na arena folclórica denominada de Bumbódromo, onde desfilam figuras saídas do imaginário caboclo. Tudo é preparado cuidadosamente, durante meses, para ser revelado em três espetáculos completamente diferentes, em dias consecutivos, fazendo a glória dos habilidosos artistas locais. A festa, de estrutura rígida, em que as lendas e rituais indígenas e figuras regionais são quesito obrigatório, mostra a riqueza da cultura e do folclore amazônico.

Tanto o Boi Garantido como o Boi Caprichoso foram criados por pessoas humildes da região, como Lindolfo Monte Verde, fundador do Garantido, primeiro amo e tirador de toadas que fez nascer um boi de brinquedo pelos idos de 1913. A ideia de fazer um folguedo surgiu das lembranças que tinha do avô, ex-escravo que saiu do Maranhão e aportou em Parintins, provavelmente no período da borracha. No começo, a função era realizar uma folia que matasse a saudade e divertisse os adultos e crianças das vizinhanças, entretanto tendo sido ferido ao servir o Exército, Lindolfo fez promessa a São João Batista para recuperar o ânimo e a saúde. Atendido o voto, veio a obrigação de todos os anos honrar o santo com o folguedo. Lindolfo Monte Verde, e com ele Luiz Pereira, conservaram a tradição até 1980, quando foram afastados do evento por uma diretoria empresarial rica e poderosa. As famílias Monte Verde e Pereira vivem hoje de forma miserável, assistindo, a distância, à luxuosa festa da qual foram criadores.

O evento encontra-se na sua $42^{\mathrm{a}}$ apresentação e aufere a cada ano uma massiva participação de vários estados brasileiros, como também de outros países. Mesmo reconhecendo o valor cultural que esse evento representa para a sociedade parintinense, questionam-se os benefícios para a melhoria das condições de vida da população. Constata-se que, a cada ano, a população local se mobiliza com o intuito de ganhar seu sustento em apenas três dias de 
duração do evento. Diversos são os produtos comerciais oferecidos pelos vendedores ambulantes e os donos das barraquinhas de artesanato, entre outras atividades comerciais do período. É importante registrar o fato de que parte significativa desses produtos não é produzida no município de Parintins e vem dos municípios circunvizinhos.

Na evolução dos bumbás, ressalta-se a participação da mídia, da indústria cultural e do turismo, de agências governamentais e amplas camadas da sociedade.

Dimensão cultural. Para esta pesquisa, entende-se que o ritual dos bumbás realiza a síntese metafórica dos aspectos simbólicos da realidade de Parintins e, consequentemente, da cultura local. Originário do Maranhão, mostra a lenda de dois trabalhadores rurais: Pai Francisco e Mãe Catirina. Conta a lenda que Mãe Catirina, grávida, deseja comer a língua do boi mais bonito da fazenda onde trabalhava com o marido. Para satisfazer o desejo da mulher, Pai Francisco manda matar o boi de estimação do patrão. Pai Francisco é descoberto, tenta fugir, mas é preso. Para salvar o boi, e consequentemente o casal infrator, um padre e um médico são chamados (o pajé, na tradição indígena) e o boi ressuscita. Pai Francisco e Mãe Catirina são perdoados pelo patrão e há uma grande comemoração.

As lendas e mitos amazônicos que enriquecem o sentido do ritual dos bois são:

- os guardiões e protetores da floresta - curupira, boitatá, caipora, muiraquitã;

v os envolvidos em questões afetivas/pessoas que se transformam em elementos da natureza - Cunhã Poranga, boto, açaí, guaraná, tambatajá, vitória-régia, uirapuru, mandioca, peixe-boi, lua, rios, sol, cobra Norato, ceuci, pirarucu;

v os ameaçadores - matinta perêra, quem-te-dera, mapinguari;

v origem e morte da vida, dos rios e lugares - cobra-grande, eldorado, amazonas, entre outros.

As lendas e mitos sinalizam para os pressupostos de alguns traços da cultura de Parintins: ligação muito forte com a natureza e consequente amor, respeito e medo com relação as suas manifestações; elaboração da perda de pessoas amadas as transformando em elementos da natureza tais como astros celestes, plantas, animais e rios; e explicação mágica para os fenômenos naturais e materiais. 


\section{Síntese do discurso dos atores internos}

Os atores internos do processo exercem as funções que viabilizam o funcionamento das organizações promotoras do evento dos bois-bumbás, ou seja, gerência superior, gerência intermediária e atividades técnicas. A função de gerência superior, não remunerada, é exercida pelos presidentes das organizações. A função de gerência intermediária, de remuneração episódica, é exercida pelos diretores de teatro e arena e pelo diretor de arte, que coordenam os núcleos de artistas responsáveis pelos elementos de formatação estética do boi-bumbá teatralizado na arena: cenografia, indumentária, desempenho dos dançarinos e dos atores, entre outros.

As funções técnicas são remuneradas e exercidas: pelo apresentador/ animador, que é o mestre de cerimônias do espetáculo artístico, dentro da arena do Bumbódromo, e que atua comentando, informando e divulgando para os jurados o espetáculo teatral; pelo responsável pela batucada, que tem como papel preparar e ensaiar com os instrumentistas todas as toadas e criar várias situações de toque para serem apresentadas na arena; e pelo levantador de toadas, cuja incumbência é cantar todas as toadas e produzir os CDs com as músicas de cada evento.

Como se pode observar no quadro 2, a emergência dos atores sociais internos ocorre de duas formas no caso da escolha da presidência: no Garantido, pelo convite para pessoas que, embora sejam oriundos de Parintins, possuem qualificações gerenciais e técnicas; e, no Caprichoso, de modo mais espontâneo, com a valorização de pessoas da própria comunidade. As gerências intermediárias e os técnicos são escolhidos nas duas fundações pela competência técnica. É importante observar que alguns agentes do processo são pessoas da comunidade que foram estudar em centros mais avançados e que depois retornaram à sua cidade de origem.

Com relação à presença de possíveis traços da cultura brasileira, verifica-se a hierarquia, quando a estrutura da organização é piramidal; e a centralização do poder formal pelos homens, pelo fato de que todas as funções institucionais de comando importantes da associação são exercidas por elementos do sexo masculino. A maioria dos contratados legais também é de homens. Existe um número pequeno de mulheres em atividades subalternas e "femininas" na parte operacional da costura, adereços e chapéus.

A cultura amazônica vem dar sentido ao ritual quando as mulheres aparecem entre os participantes do espetáculo para o público, exibindo beleza e sensualidade, resgatando por exemplo o grande mito do folclore amazonense: 
Cunhã Poranga. Ou seja, a da mais bela moça da tribo que irradia beleza nativa, olhar selvagem e um lindo corpo emoldurado de penas para seduzir a plateia.

A primeira grande contradição observada reside no fato de que o Boi Garantido, talvez por suas origens, considerado o boi do "povão" - e que a partir dos anos 1990 passou a ser comandado por um grupo de grandes empresários, é administrado de acordo com os preceitos da administração moderna, que valoriza a competência formal. Esse fato sinaliza para apropriação, pelo capital, de um evento cultural, e remete a Fernandes (1987), quando ele constata como características da revolução burguesa no Brasil as mudanças promovidas pela elite para que não seja mudado o status quo e o consequente processo de acumulação do capital.

Por outro lado, o Caprichoso, percebido como o boi de elite, tem como presidente uma pessoa com escolaridade média e surgida da própria comunidade.

A lógica do capital se manifesta quando os presidentes exercem o papel de empresários fora das associações e um deles, não por acaso, foi anteriormente diretor financeiro da associação.

A troca do nome de origem latina/portuguesa de alguns componentes por nomes ingleses indica influência americana na definição da identidade pessoal.

Com relação às redes de cooperação, observa-se que, na percepção dos presidentes, elas envolvem os atores externos da comunidade, e que, na percepção dos gerentes intermediários e técnicos, elas se referem às equipes internas simbolizadas no conselho de arte. A primeira visão tem como foco a captação de recursos financeiros e a segunda a qualidade do desempenho dos bois. Em nenhuma das visões, verifica-se pelo discurso dos atores a internalização do conceito de redes de cooperação mútua, de acordo com a concepção do DLS.

Nesse item, mais uma vez, são reforçadas nas falas dos respondentes as questões da hierarquia, autoritarismo, tendência à centralização do poder dentro dos grupos sociais e distanciamento nas relações entre diferentes grupos sociais, traços da cultura brasileira.

A ideologia burguesa dominante é manifestada na fala do presidente do Garantido, quando ele exalta as empresas internacionais representantes do capital estrangeiro colaboradoras do evento, considerando apenas o status e os aspectos financeiros. Em nenhuma fala, é percebida a valorização dos sujeitos da história dos bois, de outras contribuições da comunidade, das lideranças locais, culturais ou sociais. 


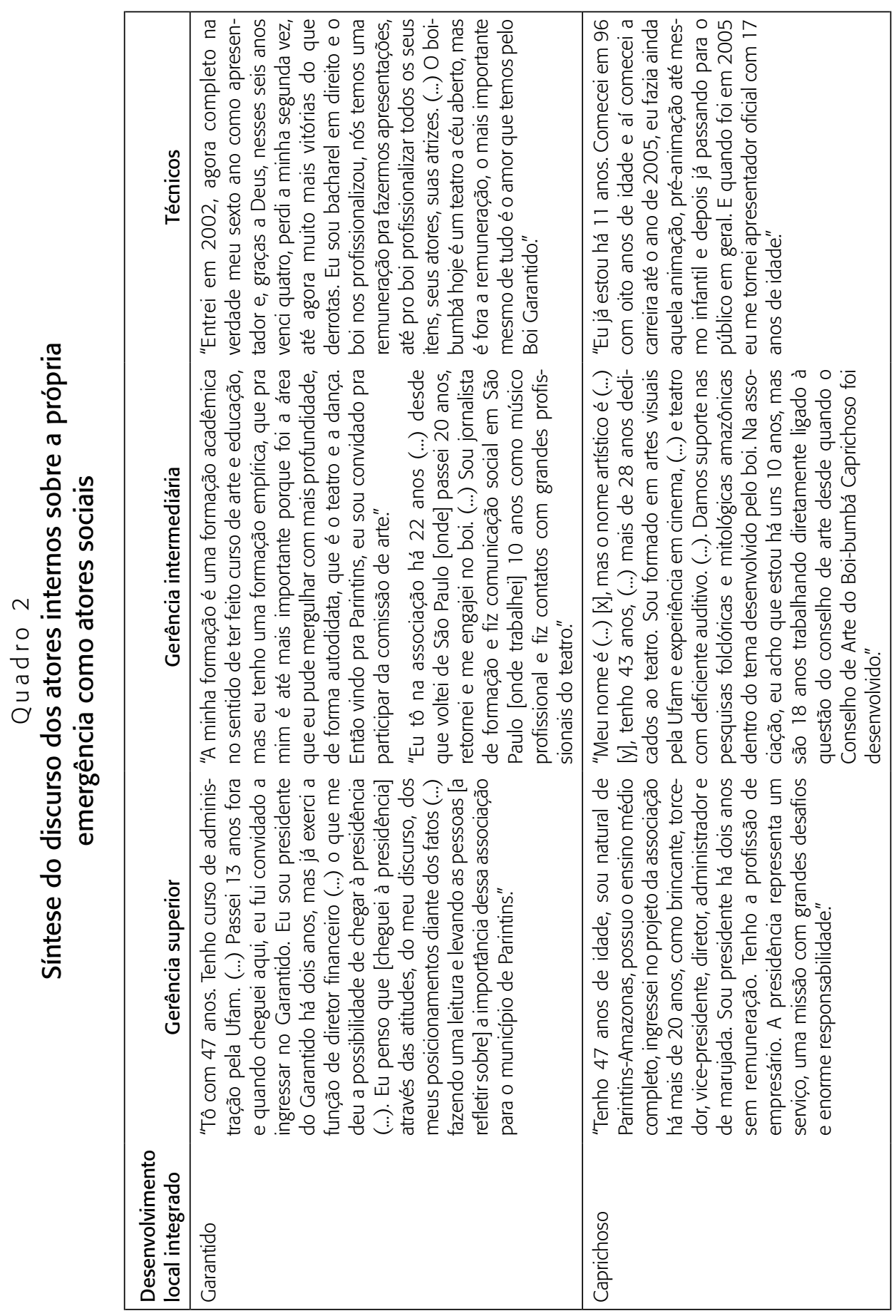




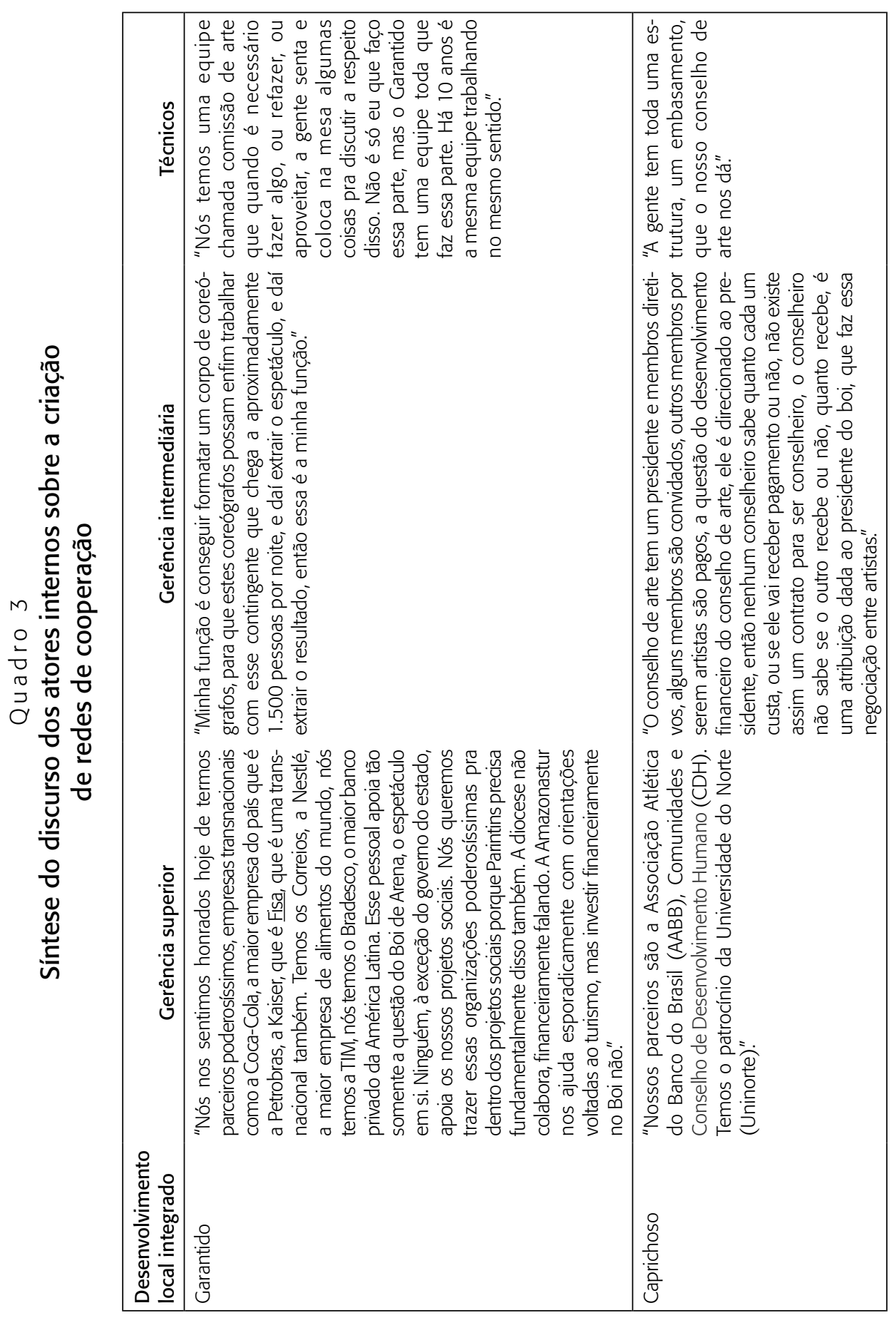




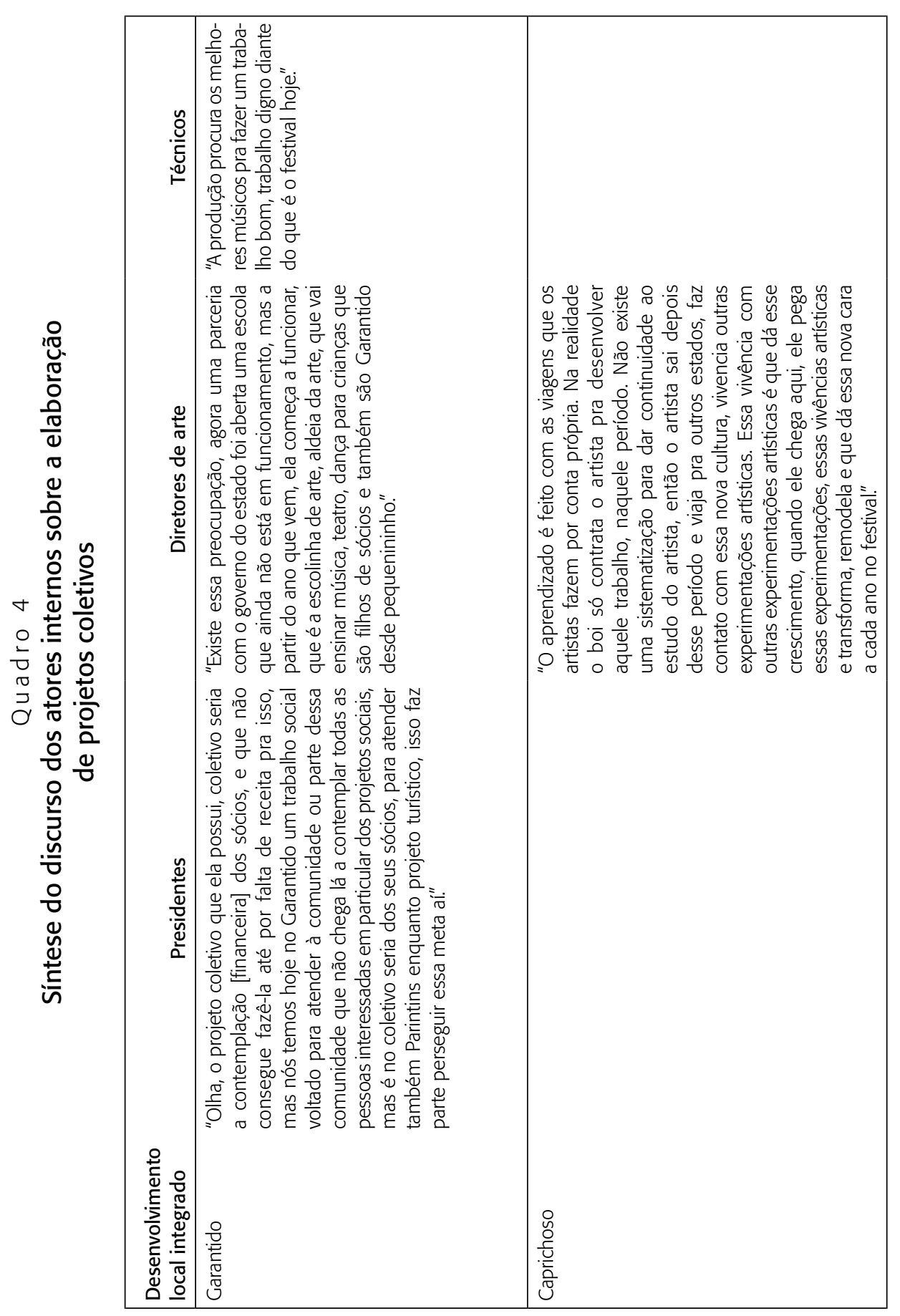


Para as gerências intermediárias e técnicos o conselho ou comissão de arte seria o grande articulador da rede de cooperação interna ao procurar nos elementos da cultura indígena os argumentos que façam sentido e mobilizem os atores internos e a comunidade e permitam a construção e desenvolvimento do espetáculo.

Pelo que se pôde observar no quadro 4, os respondentes têm dificuldade de falar sobre esse tema. O presidente do Garantido sinaliza em sua fala que projeto coletivo significa remuneração dos componentes associados dos bois, cerca de 2.500 indivíduos, o que revela a lógica capitalista dominante, cujo foco é sempre o resultado econômico. Existem alguns ensaios de projetos coletivos como a idealização de uma escolinha de arte, Aldeia da Arte, cujo nome remete à cultura indígena.

A fala do diretor de arte do Caprichoso, ao se referir ao seu desenvolvimento pessoal sem o apoio da associação ou do governo, revela o personalismo das opções individuais e a malandragem representada no "jeitinho brasileiro" de navegar socialmente.

$$
\text { Quadro } 5
$$

\section{Síntese do discurso dos atores internos sobre instituições}

\begin{tabular}{|c|c|}
\hline $\begin{array}{l}\text { Desenvolvimento } \\
\text { local integrado }\end{array}$ & Presidentes \\
\hline Garantido & $\begin{array}{l}\text { "O Garantido surgiu em } 1913 \text { (...), a associação (...) existe há } 25 \text { anos" para apresentar } \\
\text { a Amazônia, a cultura amazônica e a cultura do boi-bumbá. Possui cerca de } 1.900 \\
\text { sócios e mobiliza cerca de } 2.500 \text { pessoas. } \\
\text { "O boi-bumbá é uma variação do bumba-meu-boi do Maranhão e aqui incorporou } \\
\text { fundamentalmente o lendário indígena. A mitologia indígena, que realmente é um } \\
\text { negócio muito bonito, onde os artistas após fazerem uma leitura das lendas, ou da } \\
\text { criação ou da gênese, ou do extermínio de uma nação. Todas as nações e etnias } \\
\text { [indígenas] têm como elas foram criadas e pós-morte o que acontece com eles. Todos } \\
\text { eles têm essa história, essa questão mitológica, essas lendas e aí o artista pode fazer } \\
\text { uma leitura daquela e ele viaja naquilo e vai desenhando, criando. Primeiramente o } \\
\text { desenho, pra depois executar aquilo nos moldes alegóricos e resulta no que acontece } \\
\text { no Bumbódromo." } \\
\text { "A Amazônia, mesmo para as pessoas que não a conhecem, quando é falada em } \\
\text { qualquer lugar do mundo suscita uma curiosidade, suscita um interesse. Então é uma } \\
\text { grande marca, é uma grande grife, resta-nos saber vendê-la lá fora, usufruir do potencial } \\
\text { dela em benefício da comunidade que aqui vive, dos habitantes da Amazônia." }\end{array}$ \\
\hline Caprichoso & $\begin{array}{l}\text { "Além da tradicional história do grupo que vem desde 1913. Este passou a ser } \\
\text { associação legal em 1996." O Caprichoso conta "com a participação de } 717 \text { sócios } \\
\text { fundadores". } \\
\text { "O boi-bumbá explicita as figuras típicas regionais mais importantes e que expressam } \\
\text { concretamente a vida e a realidade amazônica." }\end{array}$ \\
\hline
\end{tabular}


Com relação ao quadro 5, observam-se mais uma vez os traços da cultura brasileira representados na hierarquia e no personalismo, quando apenas os presidentes falam sobre a associação como instituição. A fala também expressa o resgate dos elementos da cultura indígena para dar significado ao ritual do boi.

Pelo tempo de criação das associações, pode-se concluir que o grande projeto coletivo do município de Parintins é o fenômeno dos bois, existente há 95 anos, entretanto, sua institucionalização, mediante a criação das associações, somente aconteceu há 25 anos.

Pelo discurso do presidente do Garantido, contudo, essa iniciativa comunitária já se insere na lógica do capital e se torna uma mercadoria para ser vendida, com a justificativa de que a venda traria benefícios para os habitantes da Amazônia.

\section{Conclusões}

Considerando:

v os sinalizadores de sucesso do DLS, tais como a emergência de atores sociais, a formação de redes de cooperação, o desenvolvimento de projetos coletivos e a criação de sistema institucional;

v a dimensão sistêmica da realidade regida pela lógica do capital;

v os traços da cultura brasileira representados na hierarquia, personalismo, malandragem, sensualismo, espírito aventureiro e conservadorismo, podese inferir que os pressupostos da pesquisa foram confirmados.

Com relação ao DLS, observou-se, pelo discurso dos atores internos, que, embora o evento favoreça a emergência de atores sociais e as fundações Garantido e Caprichoso em sua origem sejam fruto de um projeto coletivo, ainda não existem internalizados, nesses indivíduos, os conceitos de desenvolvimento local sustentável.

No que concerne à dimensão sistêmica da realidade, verificou-se que o índice de desenvolvimento humano (IDH) em Parintins nos últimos 10 anos vem melhorando nos indicadores análises educacionais e de longevidade da população, e decaindo em renda. A crescente profissionalização do evento não reverteu em renda para a população e o estado passou a colocar recursos no município. Pela fala do dirigente do Garantido, observa-se também que 
o evento do boi-bumbá está se transformando em mercadoria subsumida às necessidades do capital.

Relativamente à dimensão simbólica, existem elementos da cultura brasileira (hierarquia, personalismo, malandragem, sensualismo, conservadorismo e religiosidade) presentes na cultura local de Parintins, representada pelo evento dos bois-bumbás. A cultura local sustentada por uma forte ligação com a natureza e consequente amor, respeito e medo com relação às suas manifestações - que sinaliza para uma consciência ecológica fundamental para o DLS - está sendo fortemente influenciada pela ideologia capitalista. Os outros elementos da cultura local tais como a forma de elaboração da perda e a explicação mágica para os fenômenos naturais e materiais podem representar fuga da realidade e dificultam a implementação do DLS.

Finalmente, é importante lembrar que o ritual dos bumbás, pleno de significados e síntese metafórica da realidade de Parintins, nasce na tensão das relações de classe, representadas pelo capital (proprietário rural) e trabalho (agricultor) e de uma transgressão nesse liame de dominação. A lenda relata que um homem do povo rouba o boi do patrão para satisfazer o desejo da mulher grávida (Eva?) de comer a língua (possibilidade de fala) do boi. Ele é descoberto, tenta fugir e é preso. O pajé - que em Parintins incorpora o padre e o médico da cultura maranhense, e que sintetiza a salvação pela fé e a resolução de problemas pela ciência - ressuscita o boi, o homem trabalhador e sua mulher são perdoados e há grande comemoração.

Esse ritual, em que o sagrado (promessa feita ao santo por Lindolfo) e o profano (festa para pagamento da promessa) se integram, incorpora, pois, a elaboração artística da percepção do povo com relação à vida, à realidade amazônica e à própria cultura. Ele também expressa a forma como o povo entende a luta implícita de poder e a tentativa de buscar solução para os problemas pela fé e pela ciência e o desejo e a esperança de uma grande conciliação apoteótica. A luta política de classe mostra-se no enredo da trama de forma dissimulada e não é explicitada como tal, nem se efetiva, e a tensão é deslocada para a luta entre os "iguais" — os bois das duas associações. Na época de festival, a rivalidade é tão grande entre os simpatizantes de cada boi que eles se recusam a pronunciar o nome do boi "contrário", ou seja, do opositor. A dificuldade de lidar com o conflito é manifestada na proibição de vaias, palmas, gritos ou qualquer outra demonstração de expressão, quando o "contrário" se apresenta.

Schein (apud Freitas, 1991) vislumbra a cultura como um aprendizado coletivo ou compartilhado, que uma unidade social ou qualquer grupo desenvolve como sua capacidade para fazer face ao ambiente externo e lidar 
com suas questões internas. A autora aponta dois mecanismos interativos que possibilitam o aprendizado da cultura: redução da dor e ansiedade e reforço/ recompensa positiva. $\mathrm{O}$ primeiro mecanismo diz respeito à ansiedade derivada da incerteza que uma pessoa tem a respeito de sua capacidade de sobreviver e ser produtivo no grupo. O problema com o primeiro mecanismo de aprendizagem é que uma vez que os indivíduos aprendam a evitar situações penosas, eles continuam a perseguir esse curso sem testar se o perigo realmente existe. No segundo mecanismo, as pessoas repetem o que funciona e abandonam o que não funciona. Nesse tipo, as respostas produzidas estão sendo testadas continuamente no ambiente, o que permite maior rapidez de adaptação. Pode, no entanto, se originar um comportamento resistente à mudança se o ambiente for inconsciente, produzindo sucesso em um momento e fracasso em outro. Nos bois a redução da dor e da ansiedade é feita em forma de catarse na participação no evento, que, pelo trabalho em si e pelo reconhecimento do público, se transforma em recompensa positiva aliviando as tensões sociais e dificultando a transformação social.

\section{Referências}

AGENDA 21. Conferência das Nações Unidas sobre meio ambiente e desenvolvimento - 1992. Brasília: Senado Federal, 1996.

ALBUQUERQUE, Francisco. Desenvolvimento local e distribuição do progresso técnico, uma resposta às exigências do ajuste estrutural. Fortaleza: Banco do Nordeste, 1998.

BRITO, L. M. P. Desenvolvimento local - alternativa de desenvolvimento sustentável no capitalismo? In: ENEGEP, 26., Fortaleza, 2006. Anais... Rio de Janeiro: Oficina das Letras, 2006. Ética e responsabilidade social, v. 1. p. 341.

BUARQUE, Sergio C. Metodologia de planejamento do desenvolvimento local e municipal sustentável. Brasília: IICA, 1998.

CEPAL (Comissão Econômica Para América Latina). Transformação produtiva com equidade. A tarefa prioritária do desenvolvimento da América Latina e do Caribe nos anos 1990. Santiago [s.n.].

COLÓQUIO INTERNACIONAL SOBRE PODER LOCAL, DESENVOLVIMENTO E GESTÃO SOCIAL DE TERRITÓRIOS, 10., Salvador, 2006. Caderno de Resumos... Salvador: Ciags/UFBA, 2006. 
CUNHA, Euclides da. Os sertões. Brasília: Francisco Alves, 1995.

DENZIN, Norman K.; LINCOLN, Yvona. A disciplina e a prática qualitativa. In: ; ___ (Orgs.). Planejamento da pesquisa qualitativa. Porto Alegre: Artmed, 2003.

FAORO, Raymundo. Os donos do poder. Rio de Janeiro: Globo, 1989.

FERNANDES, Florestan. A revolução burguesa no Brasil. São Paulo: Guanabara, 1987.

FERREIRA, Rosilda A. Invenções educacionais no âmbito do poder local: os impactos do Programa de Erradicação do Trabalho Infantil (Peti) na política educacional do município de Vivência/PE. In: SEMINÁRIO DE AVALIAÇÃO DE POLÍTICAS PÚBLICAS, 23., Salvador, 2003. Anais... Salvador: Instituto Internacional Universitário do Brasil, 2003.

FLEURY, M. T. L.; FISCHER, R. M. Cultura e poder nas organizações. São Paulo: Atlas, 1996.

FLICK, Uwe. Uma introdução à pesquisa qualitativa. Porto Alegre: Bookman, 2004.

FREIRE, Gilberto. Casa-grande e senzala. Rio de Janeiro: Record, 1995.

FREITAS, M. Ester. Cultura organizacional: formação, tipologias e impactos. São Paulo: Makron, 1991.

HOLANDA, Sérgio Buarque de. Raízes do Brasil. Rio de Janeiro: José Olympio, 1994.

LARAIA, Roque de Barros. Cultura, um conceito antropológico. Rio de Janeiro: Zahar, 1989.

MANTEGA, Guido. Economia política brasileira. Petrópolis: Vozes, 1987.

MARX, Karl. O capital. São Paulo: Nova Cultural, 1985. v. 1.

MOTTA, F. C. P.; MIGUEL, P. C. (Orgs.). Cultura organizacional e cultura brasileira. São Paulo: Atlas, 1997.

MILANI, C. Teorias do capital social e desenvolvimento local: lições a partir da experiência de Pintadas (Bahia, Brasil). In: CONFERÊNCIA REGIONAL ISTR-LAC, 4. Anais... San José, Costa Rica, 2003.

PNUD (Programa das Nações Unidas Para o Desenvolvimento). Atlas de desenvolvimento humano. 2000. Disponível em: <www.pnud.org.br>.

PRADO JR., Caio. Formação do Brasil contemporâneo. São Paulo: Brasiliense, 1987. 
REIS, Ana Carla Fonseca. Economia da cultura e desenvolvimento sustentável. São Paulo: Manole, 2007.

SCHEIN, E. Organizational culture and leadership. San Francisco: Jossey-Bass, 1986.

TEISSERENC, Pierre. As políticas de desenvolvimento local, abordagem sociológica. Paris: Econômica, 1994. (Coleção Coletividades Territoriais).

TEIXEIRA, Francisco J. S. Pensando com Marx. São Paulo: Ensaio, 1995.

WU, Chin Tão. Privatização da cultura. São Paulo: Boitempo, 2006.

YIN, Robert K. Estudo de caso — planejamento e métodos. Porto Alegre: Bookman, 2005. 